\title{
A View from Cheyenne Mountain: Generation III's Perspective of Keystone III
}

\author{
Generation III-Keystone III \\ Working Group \\ Generation III-Keystone III Working \\ Group Members: Erika Bliss, MDi Kara \\ Cadwallader, $\mathrm{MD}_{i}$ Terrence E. Steyer, $\mathrm{MD}$ \\ Deborah S. Clements, $\mathrm{MD}_{i}$ Jennifer E. \\ DeVoe, $\mathrm{MD}_{i}$ Kenneth Fink, MDi Marina \\ Khubesrian, $\mathrm{MD}_{i}$ Paul Lyons, $\mathrm{MD}_{i}$ Elizabeth \\ Steiner, $\mathrm{MD}_{i}$ and David Weismiller, MD
}

\begin{abstract}
In October 2000 the family of family medicine convened the Keystone III conference at Cheyenne Mountain Resort. Keystone III participants included members of Generation I (entered practice before 1970), Generation II (entered 19701990), and Generation III (entered after 1990). They represented a wide range of family physicians, from medical students to founders of the discipline, and from small-town solo practice to academic medicine. During the conference, the three generations worked together and separately thinking about the past, present, and future of family medicine, our roles in it, and how the understanding of a family physician and our discipline had and would continue to evolve. After the conference, the 10 Generation III members wrote the article published here, reflecting on our experiences as new physicians and physicians in training, and the similarities and differences between our experiences and those of physicians in Generations I and II. Key similarities included commitment to whole-person care, to a wide scope of practice, to community health, and to ongoing engagement with our discipline. Key differences included our understanding of availability, the need for work-life balance, the role of technology in the physician-patient relationship, and the perceptions of the relationship between medicine and a range of outside forces such as insurance and government. This article, presented with only minor edits, thus reflects accurately our perceptions in late 2000. The accompanying editorial reflects our current perspective.
\end{abstract}

Ann Fam Med. 2014;75-78. doi: 10.1370/afm.1606.

\section{INTRODUCTION}

S ince becoming a board-certified specialty in 1969, family medicine has evolved in response to numerous factors, including a broadening of the populations served and the complexity of the health care delivery system. During the ensuing 3 decades, ${ }^{1}$ Keystone conferences have been convened at Cheyenne Mountain Resort to review the intellectual basis and development of family medicine, "to take stock of our history and future prospects," ${ }^{2}$ and to "recapture some of our original enthusiasm and informality in talking to each other about our ideas and experiences, to share that among generations of leaders." ${ }^{\prime 3}$ The Keystone III conference, held in October 2000, continued this tradition, making a special effort to ensure that participants were selected from all 3 generations of family medicine leaders: those who entered practice before 1970, between 1970 and 1990, and after 1990. For third-generation participants (Generation III), this opportunity was unique, because "young physicians need to gain insight into their motivations, to learn how and when to use their personhood on behalf of patients. ...[Hiram Curry] speaks to the essence of being a physician rather than a mere doctor of medicine."4 Generation III family physicians' ideas about family medicine may differ in ways from the ideas of those who founded the specialty, yet we continue to contribute to the same "different way of doctoring," as described by Lynn Charmichael. ${ }^{4}$ Generation III practitioners, educators, and researchers have an unmistakable identity. While remaining committed to perpetuating the core values of family medicine, we recognize the need to change and expand our discipline. In this context, we present our view from Cheyenne Mountain.
Elizabeth Steiner, MD

Oregon Health \& Science University

3181 SW Sam Jackson Park Rd

Mail Code FM

Portland OR 97239

steinere@OHSU.edu 


\section{LOOKING BACK}

As are the views of those who came before us, Generation III's views are influenced not only by society but also by the dramatic changes in health care, medicine, and our specialty. We did not experience the birth of family medicine; we have learned about it from colleagues and historical documents. For example, we feel the power of Stan Truman's vision when in 1962 he stated:

What is needed are more family doctors to act as the family medical advisor and guide, the primary diagnostician and the primary therapist.... When the field is delineated, the quality and thoroughness of the training recognized, young men will be attracted to this field because of the rich full satisfying professional life it offers. ${ }^{5}$

What distinguished this new specialty of family medicine? Definitions abound. The American Academy of Family Physicians defined the family physician as,

...educated and trained to develop and bring to bear and practice unique attitudes and skills which qualify him or her to provide continuing, comprehensive health maintenance and medical care to the entire family regardless of sex, age, or type of problem. ${ }^{6}$

George Dean said further that family medicine must use "[a] multidisciplinary approach, referring the patient to the necessary health resource or specialist when appropriate but still preserving the continuity of care." ${ }^{17}$ Rosemary Stevens added, "The new family physician would be an expert in the patient-physician relationship and put emphasis on sociological as well as strictly scientific skills." ${ }^{18}$

Generation III family physicians embrace the themes of continuous and comprehensive care practiced with a scientific eye, a humanistic touch, and a broad expertise that includes preventive medicine, counseling, and patient education. One might argue that we cannot adequately define family medicine by what we do, but rather by bow and why we do it.

Although family medicine grew out of a centurieslong generalist tradition, it gained specialty status during the social upheaval of the 1960s, when family medicine occupied a counterculture position. ${ }^{9}$ As the energy of the social movements dissipated, Generation II family physicians transitioned into the Reagan/Bush years, when public discourse focused on shrinking government and its influence on social change. Generation III family physicians thus came of age during an era of shrinking social activism. Although many still dedicated their lives to activism and service, they accepted a more narrowly focused, incremental approach.

In the health care arena, Medicaid and Medicare grew in size and bureaucratic complexity as privatization proliferated, with private health insurers treating health care as a commodity to be bought and sold in the marketplace. Many Generation II family physicians joined forces with health maintenance organizations in the 1980s as a step toward realizing family medicine's goal of universal health care. The current health care system became managed by these and other employersponsored private health care plans, alongside the publicly subsidized health care programs, a context that has become increasingly complicated and irrational.

\section{GENERATION III FAMILY PHYSICIANS}

Reflecting the general population, the face of medicine has changed during the last 20 years. There are more women and minorities in medicine, and a greater number of medical students have entered family medicine. With this diversity, family medicine has gained new perspectives and expectations.

Physicians are contending with increasing intrusions into the physician-patient relationship. Such intrusions are more onerous for family medicine than for other specialties as we strive for continuity of care and strong patient relationships. As insurers squeeze savings and profit from the system, the practice of medicine has become more stressful and potentially unpleasant. The burden of risk and cost sharing, disproportionately shouldered by primary care providers, has placed family physicians in difficult practical and ethical binds. The transformation of medical care into a major industry has cast family physicians into a worker rather than a professional role.

New technology has brought exponential increases in new products, services, and expectations to the lives of average citizens. Generation III family physicians are comfortable with new technology, but we have experienced the transition and can appreciate the startling changes of the technology revolution. Health care has been slow to catch up, and most medical students still learn in a system designed to meet the needs of doctors at the turn of the 20th century. Faced with a barrage of information and told that $50 \%$ of this information would be obsolete by the time we completed medical school, we have been challenged, not by the need for a more prestigious field, but by the daunting task of becoming and continuing to be competent family physicians.

Family medicine has made remarkable inroads into academia during the last 30 years. Despite this success, the specialty does not present a consistent and inspiring message. Family physicians' discontent with a broken health care system has spilled over into training environments. In this context, we cannot fault our colleagues who listened to their specialist mentors and steered clear of the generalist role. Many of us who chose to join Generation III family physicians have encountered 
little of the principles, core values, and history of our specialty, and insufficient venues exist in which to discuss the larger issues. Family medicine appears to be in survival mode-we are racing to keep up with rapid changes in medicine and becoming more like our specialist colleagues, who focus on the details at the expense of the larger picture. This survival mentality can be found among our newer physician colleagues, who see themselves working in jobs, stereotyped as lacking activism and commitment to the principles of family medicine.

In light of this stereotype and the recent discussions highlighting struggles and missed opportunities in family medicine, Generation III hopes to participate in a revitalization of family medicine in today's social context.

\section{LOOKING AHEAD}

Generation III family physicians chose their specialty for a variety of reasons: the emphasis on individual relationships with patients, the challenge of tackling whatever problem a patient presents, and the potential for creating social change through our work. We like the emphasis on care, not just cure; we want the opportunity to treat people, not diseases. We believe that family medicine plays an important role in improving the health and well-being of our society. We are fulfilling a lifelong dream of becoming a doctor in the broadest sense of the word. Although Generation III represents perhaps the most diverse group of family physicians, we join Generations I and II in our commitment to providing patient-centered, accessible, continuing care to patients, their families, and communities. We value an integrated system of care with multidisciplinary contributions. These core values, which must be preserved, must also be redefined and revitalized (but not reinvented) within the diversity of today's social context.

As have those before us, we must first embrace new definitions of family and community, as well as the scope and nature of practice. The definition of family has been expanded to include a variety of family units, and communities go beyond geographic boundaries. New faces and new perspectives challenge us to rethink the practice of family medicine. Traditionally, the physician (usually male) could depend on the support of a wife, family, and community to sustain his hectic, dedicated lifestyle. Today's physicians face a different lifestyle. Households are headed by 2 adults working outside the home, and a greater mobility compromises the network of community support: young families are living geographically apart from grandparents and other relatives, in neighborhoods where most adults are gone during the day. Within this context, we struggle to balance families and careers. Even in the absence of children and marriage, many Generation III family physicians reject the notion of having to be available to our patients all the time and find great satisfaction and continuity of relationships on a part-time basis.

Traditional professional roles are further challenged as we redefine them to embrace contributions from our colleagues that broaden the scope and nature of practice. In addition to practicing family physicians who work in teams to provide full-time care for patients, we recognize the importance of having a specialtydriven intellectual enterprise to develop our discipline's knowledge base. The roles of researcher and policy analyst, formerly considered emblematic of what was wrong with medicine, are now recognized as essential intellectual pursuits that must become a part of how our specialty projects itself to medical students and the public. Mentors who reflect a diverse scope of family medicine are essential for accomplishing this mission.

The resulting redefinition of our specialty is paired with a redefinition of our strengths. Not only is there strength in numbers, but there is also strength in diversity, flexibility, and adaptability. A healthy, happy, and diverse workforce is created when the focus shifts from falling short of unrealistic promises to meeting realistic commitments. Strength can also be found in resilience (not resistance). Generation III family physicians possess a strength that comes from experiencing that changes are inevitable. To function within the US health care system, the need for such strength becomes critical. As family physicians from Generations I and II have done before us, we keep one eye on the health care system and one eye on the specialty. We want to sharpen our perspective for knowing when to change the specialty and when to change the system, how to work without becoming complacent, where to develop creative ways to find peace within a system that is driving ahead, and how to avoid getting too comfortable as we remember that the US health care system is long overdue for a pit stop and at risk for a disastrous accident.

Revitalization is driven by the newly expanded definitions, broadened scope, and diversification of roles in our practice. By recognizing the need for teamwork and partnerships to provide continuity and consistent, high-quality care, we embrace the reality of shared responsibility, developing individual strengths that will enable us to best contribute to a team that meets community needs. Family medicine is uniquely situated to ask, "What are the community's needs?" then, "How can we meet them?" We have the ability to remain flexible by relying on a variety of training opportunities.

\section{A DIFFERENT WAY OF DOCTORING}

It is a legacy of our discipline that each new generation of family physicians must revisit Francis Peabody's 
deceptively simple prescription: "The secret to the care of the patient is caring for the patient."10 We suggest that an adequate definition of family medicine includes not only how and why, but also who, participates, how they can and will participate, why they choose to do so, and ultimately, what do we do as a discipline that marks our unique role in the complex and difficult challenge of caring for the patient.

Family medicine promises comprehensive, continuous care of the patient in the context of family and community. During the last 50 years each of the 6 variables-comprehensiveness, continuity, care, patient, family, and community-has become increasingly diverse and complex. With each new technological breakthrough, comprehensiveness broadens. Continuous has evolved to mean anytime, anywhere, for any problem - a role few individuals can fill alone. In no small part because of the success of family medicine, care no longer means something as simple as the right drug for the right bugi instead, it includes physical, emotional, spiritual, and economic care. Family medicine must evolve to meet these new challenges.

Not all newly minted family physicians embrace an unreconstructed vision of a family physician. Generation III participants at Keystone III represent full-time practitioners, academic physicians, researchers, and public policy advocates, among others. Such diversity challenges the monochromatic model of a solo country doctor. Some family physicians are uncomfortable with this departure from tradition, perhaps because they perceive it as abandoning the core values of family medicine. We recognize and respect this discomfort but believe that each of us makes important contributions to the fully realized specialty. We spoke often at Keystone III about physician availability 24/7-carrying a pager, answering one's phone, and making 2:00 AM emergency department visits. For some, family medicine still means this level of availability. But this model is only one way to make health care accessible. Family medicine is not a job ${ }_{i}$ it is integral to our identity. We do not stop being family physicians when our pager is off. As family physicians, we all are available 24/7, even as we attend school board meetings or participate with our religious organizations or when, each November, we vote.

We practice family medicine because family medicine promised and continues to be the one discipline that fulfills our best and broadest vision of medicine. A commitment to all patients remains central to Generation III. This commitment is defined individually in a manner that seems best for each. For some, lack of universal health care presents a fundamental hurdle to patient care-public policy and advocacy are critical. For others, good patient care begins with modeling a healthy life balance-making time for family and community. And for still others, the continued strength of family medicine rests on the shoulders of future family physicians, best guided through their education by caring family physicians of today-teaching.

The needs of family medicine are numerous, the challenges daunting and inviting. Although Generation III participants differ in their career paths, often dramatically, none believed that their goals would be better served in a different specialty. Participants in Keystone III spoke frequently of covenant with patients and with the core values of family medicine.

Four decades have brought major changes to our society, to medicine as a whole, and to family medicine as a discipline. Despite these changes, family medicine remains not just a viable but a vibrant specialty, one that makes each of us proud to be a family physician, one that is capable of drawing future generations of enthusiastic participants. What we do is unique. Regardless of who makes up our professional fellowship, how they choose to pursue the objectives of family medicine, or why each is drawn to it, we remain the only specialty capable of saying, "Whoever you are, whatever your need might be, come to me. Together we will work it out." As Generation III surveys the view from Cheyenne Mountain, this definition of our specialty says, "young [people] will be attracted to this field because of the rich, full, satisfying professional life it offers."

To read or post commentaries in response to this article, see it online at www.annfammed.org/content/12/1/75.

Key words: history of medicine; family practice; family medicine; delivery of health care

Submitted September 23, 2013; submitted, revised September 23, 2013; accepted November 18, 2013.

\section{References}

1. Stephens GG, et al. The intellectual basis of family medicine revisited. Family Medicine 1985;17: 219-230. Fam Med. 1998;30(9):642-654.

2. Stephens GG. Advanced forum in family medicine. Fam Med. 1985; $17: 184$.

3. Stephens GG. Personal communication to the Society of Teachers of Family Medicine Foundation. Sep 24, 1998.

4. Carmichael LP. A different way of doctoring. Fam Med. 1985;17(5):4.

5. Truman, S. General practice and the general practitioner. JAMA. $1962 ; 180(12): 130$.

6. American Academy of Family Physicians. Proceedings of the Congress. Oct 1975.

7. Dean GA. Family practice, medicine's newest specialty. Mich Med. 1971;70(31):1145-1149.

8. Adams DP. Evolution of the specialty of family practice. J Fla Med Assoc. 1989;76(3):325-329.

9. Stephens GG. Family medicine as counterculture. Fam Med. 1989:21(2):103-109.

10. Peabody FW. The care of the patient. JAMA. 1927;88(12):887-892. 